\title{
Architecture proposal for a support sustem to upper limb telerehabilitation by capturing biomechanical signals
}

\author{
Propuesta de arquitectura para un sistema de apoyo a \\ telerehabilitación de miembro superior capturando señales \\ biomecánicas
}

Proposta de arquitetura para um sistema de apoio a telereabilitação de membro superior capturando sinais biomecânicos

Fecha Recepción: 10 de Julio de 2015

Fecha Aprobación: 20 de Agosto de 2015

Mauro Callejas-Cuervo* Manuel Andrés Vélez-Guerrero** Andrés Felipe Ruíz-Olaya*** Rafael M. Gutiérrez****

\begin{abstract}
This article proposes a system for Telerehabilitation of people with motor disorders of the upper limb, by making a literature review about works related with the provision of the physical therapy service with ICT's use. Likewise, there is a brief description of the modules integrating the system: motion capture system based on inertial sensors and motion capture with camera; joint angle estimator was implemented through Kalman filter; IT app which registers the electronic medical record and finally, the active videogames module.
\end{abstract}

Keywords: Upper limb rehabilitation, inertial sensors, telerehabilitation, Kalman filter, e-health.

* Ph. D. (c) Doctorado en Ciencia Aplicada (Universidad Antonio Nariño) - Universidad Pedagógica y Tecnológica de Colombia (Tunja-Boyacá, Colombia).mauro.callejas@uptc.edu.co.

** Semillero Grupo de Investigación en Software (GIS) - Universidad Pedagógica y Tecnológica de Colombia (Tunja-Boyacá, Colombia). manuel. velez@uptc.edu.co.

*** Ph. D. Universidad Antonio Nariño (Bogotá-Distrito Capital, Colombia). andresru@uan.edu.co.

**** Ph. D. Universidad Antonio Nariño (Bogotá-Distrito Capital, Colombia). rafael.gutierrez@uan.edu.co. 


\section{Resumen}

Se propone un sistema para Telerehabilitación de personas con trastornos motores del miembro superior, para lo cual se realiza una revisión de literatura sobre trabajos relacionados con la prestación del servicio de terapia física con el uso de TIC; así mismo se describen de manera breve los módulos que integran el sistema, estos son, sistema de captura basado en sensores inerciales y captura con cámara; estimador, implementado mediante el filtro de Kalman; aplicación informática que registra la historia clínica electrónica y finalmente el módulo de videojuegos activos.

Palabras Clave: rehabilitación de miembro superior, sensores inerciales, Telerehabilitación, filtro de Kalman, e-salud.

\section{Resumo}

Propõe-se um sistema para Tele-reabilitação de pessoas com transtornos motores do membro superior, para o qual se realiza uma revisão de literatura sobre trabalhos relacionados com a prestação do serviço de terapia física com o uso de TIC; igualmente se descrevem de maneira breve os módulos que integram o sistema, estes são: sistema de captura baseado em sensores inerciais e captura com câmara; estimador, implementado mediante o filtro de Kalman; aplicação informática que registra a história clínica eletrônica e finalmente o módulo de videogames ativos.

Palavras chave: reabilitação de membro superior, sensores inerciais, Tele-reabilitação, filtro de Kalman, e-saúde. 


\section{INTRODUCTION}

Telemedicine [1] is the delivery of medical services over telecommunication networks and the internet. An emerging rehabilitation practice focus on delivering physical therapy using telerahabilitation, which allows experts in different medicine fields to keep the record, evolution and diagnose of patients who are in motor rehabilitation processes and who live in places of difficult access or who do not have specialist in this area. The emerging technologies for the practice of physical rehabilitation are based on motion capture mechanisms [3-4], which allow catching biomechanical signals from some body parts and, through informatics processes, registering data on the computer. [5]. The tele-physiotherapy service integrates two scenarios geographically distributed: the location of the patient with mild motor disabilities and the rehabilitation center; these are communicated via internet, following standards for Telemedicine practice, specifically the ones related to TI apps, such as Health Level Seven International, HL7 [6]; "Digital Imaging and Communication in Medicine, DICOM [7], among other.

The proposed architecture is composed of four modules. The first module is about human motion capture based on inertial sensors and motion capture with infrared camera, which collect the motion information of a patient. The second module contains the data fusion algorithm development, based on Kalman filters, which allows estimating the angular position of the joints with accuracy. The third module integrates the informatics app that transforms captured data into valid information for a final user; in addition it will register the evolution in the therapy plan proposed by a specialist. This software will be installed in the server of the rehabilitation center and will transfer the applicable information to the computer where the patient is being cared. Finally, the fourth module will integrate the different active videogames with a console, with the purpose of executing the therapy plans suggested by the medical specialist.

\section{Preliminaries}

In the literature related to the practice and development of rehabilitation using technology, there have been found many works; for example, in the specialized database Scopus, since 1996 to date has been reported a total of 316 publications, distributed in different areas, as presented in Fig.1. For the above searching, the terms "Rehabilitation with inertial sensors" was used as standard.

\begin{tabular}{|l|c|}
\hline Subject Area & Documents \\
\hline Engineering & 199 \\
\hline Computer Science & 141 \\
\hline Medicine & 123 \\
\hline Biochemistry, Genetics & \\
\hline and Molecular Biology & 42 \\
\hline Health Professions & 29 \\
\hline Physics and Astronomy & 18 \\
\hline ChemicalEngineering & 15 \\
\hline Mathematics & 14 \\
\hline Neuroscience & 12 \\
\hline Chemistry & 10 \\
\hline Materials Science & 10 \\
\hline Arts and Humanities & 3 \\
\hline Psychology & 3 \\
\hline Business, Management & \\
\hline and Accounting & 2 \\
\hline Nursing & 2 \\
\hline Energy & 1 \\
\hline Immunology and & 1 \\
\hline Microbiology & 316 \\
\hline Total & \\
\hline
\end{tabular}

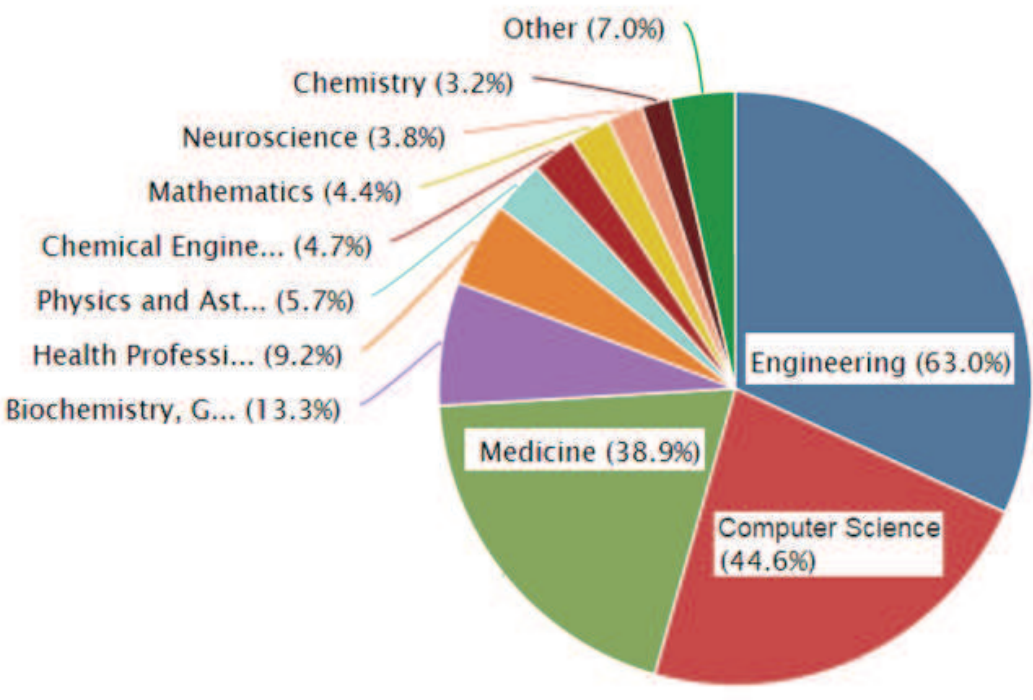

Fig. 1. Rehabilitation and use of technologies, according to Scopus database. 
Other databases such as IEEE Xplorer, cluster a total of 175 publications, of which 140 are documents presented in conferences and the remaining are published in journals and magazines, leading 2015, there are 13 publications and growing; while in Web of Science database, 85 publications are registered. In recent years, the advances in matter of inclusion of technologies for rehabilitation has shown an important increase but not as enough as it was expected; on the other hand, there are few studies integrating the inclusion of active videogames in telerehabilitation of people with motor minor injuries in the upper limb. In the study presented by Golomb et al. [9], is shown the implementation of a system of videogames based on virtual reality for the rehabilitation of teenagers with cerebral palsy, in telerehabilitation mode. Such platform presents three subsystems: the first one manages the videogame; the second captures the patient motion, and the third visualizes the virtual environment of the game. Ines and Abdelkader [10], present a Mixed Reality System for Serious Games (MRSGS) for motor rehabilitation of the upper limb after a cerebrovascular accident. The system aims at increasing the use of technology in physical recovery processes, by making the user interface highly intuitive and allowing the therapist to perform monitoring the patients, besides reducing costs on its implementation. The study posed by Burdea et al. [11], presents a rehabilitation plan based on videogames executed on a PlayStation 3 console, by using a glove with sensors integrated, focused to the rehabilitation of the upper limb, specifically the hand, highlighting that the experiment was applied in two pediatric patients with hemiplegia.

Other relevant studies in telerehabilitation even do not include videogames in its rehabilitation plans; these make use of sensors [12-14], optical motion capture [15] and robots [16-17].

\section{RESEARCH FRAMEWORK}

In the first instance, it is important placing the focus of the research, because a series of concepts about telemedicine, e-health, telerehabilitation, among others, are recognized, but no scheme is identified in a clear manner to distinguish each one of them. Fig. 2 presents a general approach.

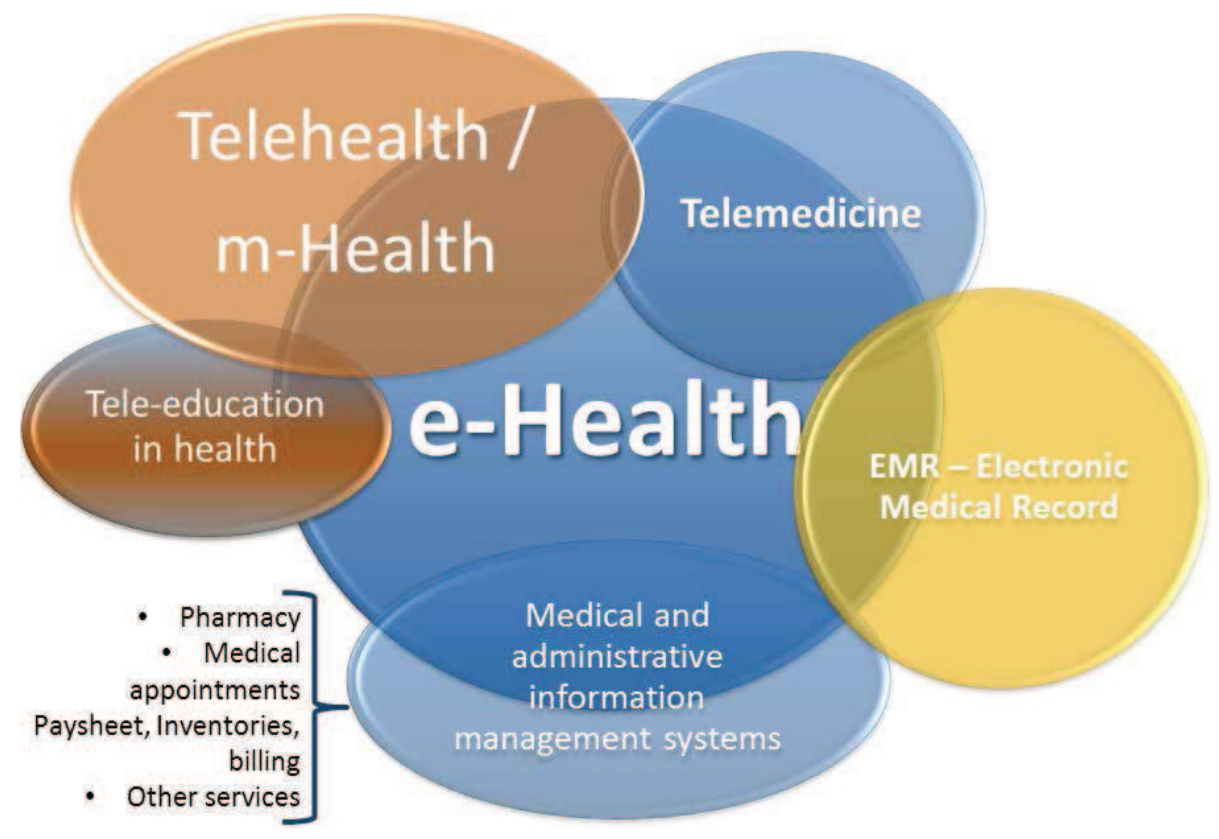

Fig. 2. Structural model of the electronic health (e-health).

In the above model, the e-health vast area is clearly identified, covering the other subareas; telehealth covers aspects such as tele-education in health and the telemedicine, this last, is the modality addressed in the present study. 
On the other hand, the proposed model is based on a distributed system which is going to be implanted in the specialized rehabilitation center and in the patient's house. In the first scenario there is a server that stores the information of the patient from his first consultation until the conclusion of the rehabilitation plan. In the second one (patient's house), the technological accessories needed for the motion capture (inertial sensor network) and an infrared camera able to catch 3D signals will be installed. Likewise, there must be connection to internet and a PC that will play the active videogames that are part of the rehabilitation process. Fig. 3 presents the scheme.
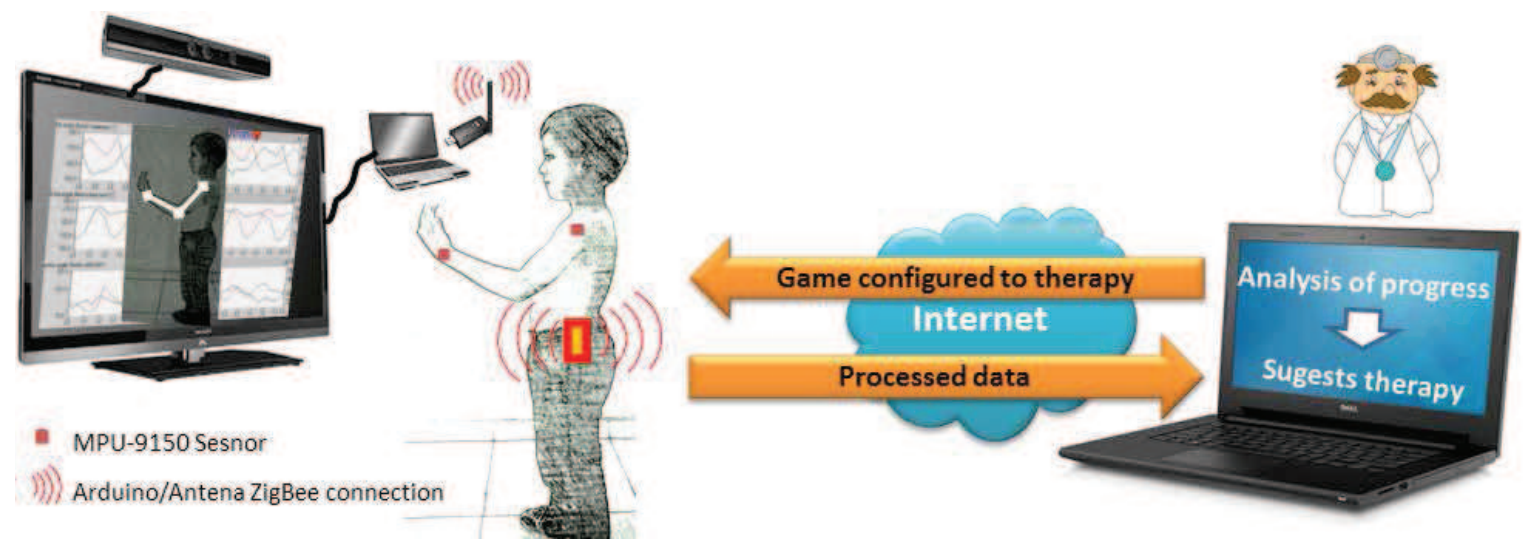

Fig. 3. Scheme of the physical telerehabilitation system.

\section{Proposed Architecture}

The modules that integrate the proposed architecture for a telerehabilitation system are described below.

\section{A. Module 1. Motion capture system}

This module is based on inertial sensors and capture with a vision system, where the first part is integrated to an inertial sensors network placed in each one of the upper limb joints, by using MPU-9150 sensors from InvenSense, which have 9 degrees of freedom; those sensors integrate accelerometer, gyroscope and magnetometer in a single chip and have low consumption and cost (Fig. 4, numeral 1). Zigbee is the wireless communication protocol between sensors, which is based on the IEEE 802.15.4 standard for personal area wireless networks; later, the signals are captured and collected to be sent to the computer (Fig. 4, numeral 2). The second part is composed of an optical system without markers, relating to an infrared camera, to a TV and to a PC; this one captures the movements made by the patient, by storing certain values on the informatics system (Fig. 4, numeral 3), and later, there is a data fusion oriented to obtain accurate information about the motion parameters. The general scheme of the motion capture module can be observed in Fig. 4 .

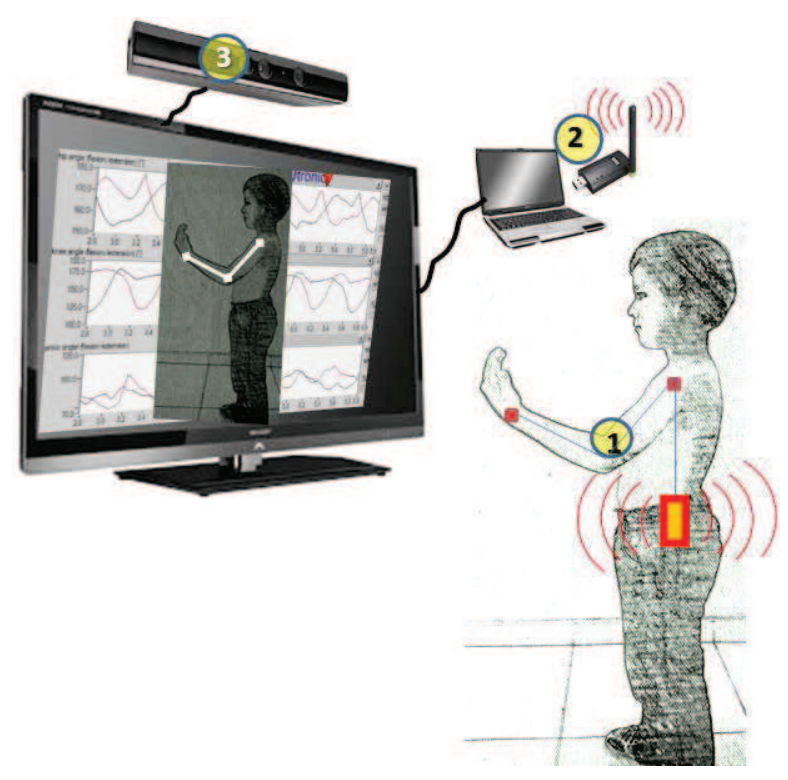

Fig. 4. Scheme of motion capture module.

\section{B. Module 2. Data fusion algorithm}

The use of an estimator such as the Kalman filter allows generating a better signal than the one obtained directly from the inertial sensors; this may guarantee 
a better quality for the captured data and may tend for calculating the angular positions of the upper limbs accurately, assuring that measurements are close to the system simulated by the proposed platform.

In order to choose the best estimator for being implemented in the platform, a bibliographic review about some of the Kalman filter variations was carried out in the aforementioned databases, obtaining the following tendencies over a total of 33 articles: 10 articles report the use of the Common Kalman filter; 12 articles report the use of Extended Kalman filter; 4 articles report the use of Unscented Kalman and the other publications report isolated cases of the using of another types of filters (Centroid Weighted Kalman Filter, Adaptive, Ensemble, Robust, Fuzzy, Particles).
From the above, it is concluded that most of the publications register the implementation of both the Extended Kalman filter as the common [18-19], because its algorithm presents good documentation that eases its implementation for different uses, versus other variants that are specific for particular action field. Moreover, it is worth noting the publication provided by Zhang et al [20], who made a comparative analysis of the extended and unscented filters, concluding that the last one has better performance and consumes less computational resource, in the case of the reported experiment. From the above, it can be proposed the implementation of the Unscented Kalman filter, but it requires making a series of tests after the implementation of the hardware and firmware architecture proposed in the present article. A block diagram of the performance of the unscented Kalman filter can be observed in Fig. 5.

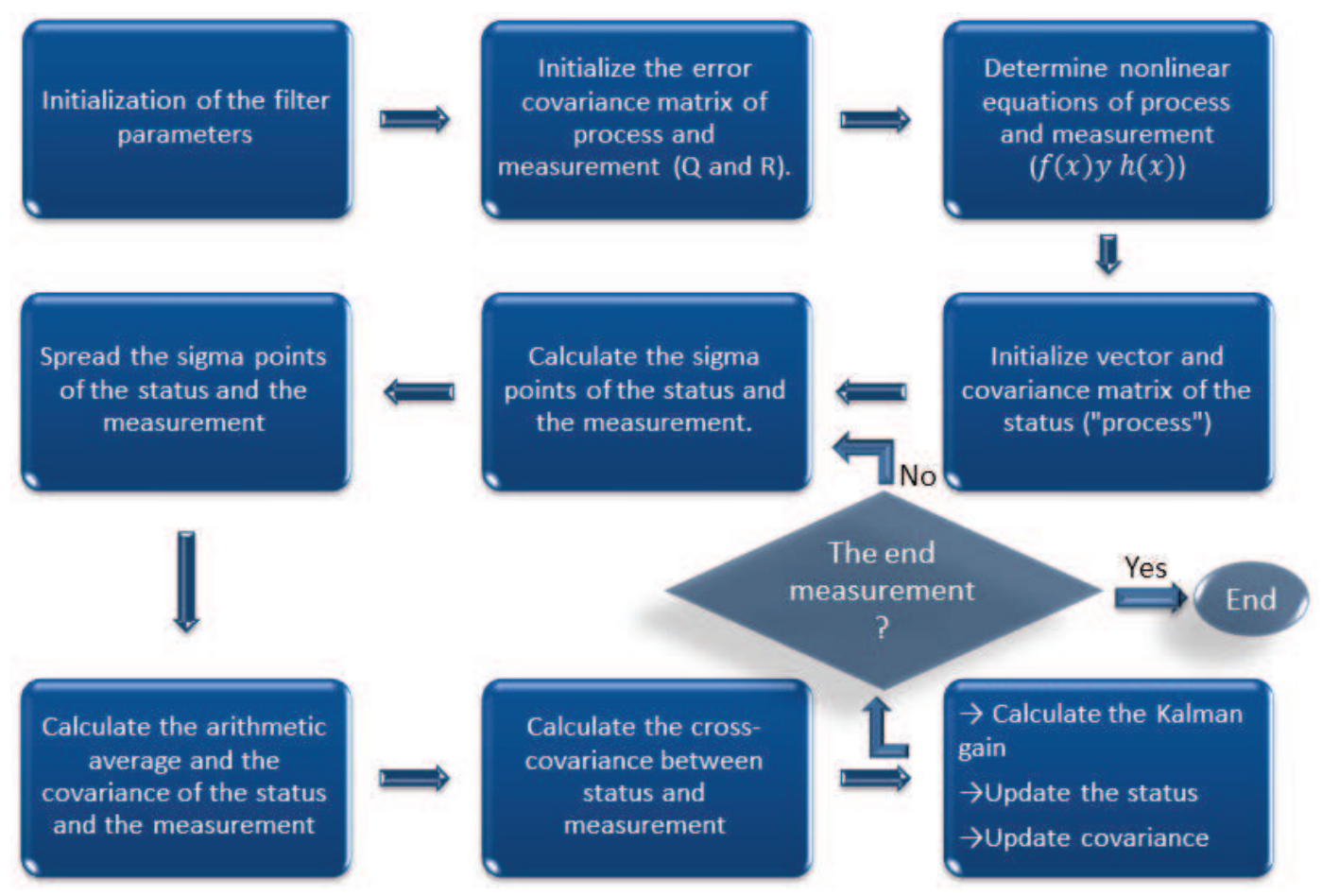

Fig. 5. Block diagram of the Kalman unscented filter.

\section{Module 3 IT application: Electronic Medical}

Record.

The third module of the system is an informatics application that allows registering and consulting the basic information of the patient, as well as the information of the therapies performed by it. The software registers the progress in the rehabilitation plan proposed by the medical specialist and manages the programming of the suggested therapy, based on the results of the analysis of the patient evolution; 
this is installed in the rehabilitation center and can be displayed on the patient's computer.

The application has the following submodules: a) Processing signals obtained from the motion capture system; b) Patient data management module; c) Module of conversion or registering of results of tests made with biomedical devices (standardized with DICOM and HL7); d) Medical records module, interoperable through DICOM and HL7.

\section{Module 4. Module of active videogames integra- tion}

This last module integrates a gallery of active videogames whose development is based on different physical rehabilitation plans, suggested by a medical specialist. The videogames are available for the specialist to propose the cycle of therapies that the patient must perform; each videogame has a difficulty level which allows auto-configuring for the patient to train until accomplishes the objective proposed in the videogame, leading the fulfillment of the purpose of the therapy plan.

The videogames are developed with $\mathrm{C} \#$ programming language and could be run with devices interactively connected to a TV.

\section{Conclusions}

The implementation of the platform will allow the development of the telemedicine modality, specifically in the physical rehabilitation of people with the inclusion of the multimodal capture of biomechanical signals.

The construction of the motion capture module is the main tool for the development of areas such as Artificial Intelligence and robotics, since through this, it is intended to develop some projects for the creation of devices that will venture in the engineering of the physical rehabilitation of people, as well as the biomechanical analysis of different species.

The modern use of videogames is beyond the leisure. Nowadays, it is in a new modality called "serious videogames", which have been applied in industry, health, education, military area and other areas that have found the way to exploit the benefits of this technology.

\section{REFERENCES}

[1] R. L. Bashshur, On the Definition and Evaluation of Telemedicine. Telemedicine Journal. vol. 1, pp. 19-30. 1995.

[2] T. Yokoishi, H. Hada, J. Mitsugi, O. Nakamura, J. Murai, "Bidirectional medication support system for medical staff and home care patients". Proceedings in 5th International Symposium Medical Information \& Communication Technology, (Montreux, Switzerland), pp. 147 - 151, IEEE, 2011.

[3] J. Martín-Moreno, M. Ruiz-Fernández, A. Soriano-Payá, V.J. Berenguer-Miralles, "Monitoring 3Dmovements for the rehabilitation of joints in physiotherapy". Proceedings In 30th Annual International IEEE EMBS, (Vancouver, British Columbia, Canada), pp. 4836 - 4839, 2008.

[4] S. F. Foo, H. Zhuo, W. Phyo, M. Jayachandran, J. Biswas, Y. Siew and P. Yap, "Innovative platform for Tele-physiotherapy". Proceedings In 10th International Conference E-health Networking, Applications and Services. (Singapore), pp. 59-65, 2008.

[5] F. Martínez, F. Gómez and E. Romero, “Análisis de vídeo para estimación del movimiento humano: una revisión". Revista Med, Vol. 17 (1), pp. 953-106, 2009.

[7] Health Level Seven International. Concepts. Available: http://www.hl7.org/, [Accessed:10Jun-2014].

[8] Digital Imaging and Communication in Medicine. Available: http://dicom.nema.org/, [Accessed:10-May-2014].

[9] M. R. Golomb, B.C. McDonald, S.J. Warden, J. Yonkman, A. J. Saykin, B. Shirley, et al. In-home virtual reality videogame telerehabilitation in adolescents with hemiplegic cerebral palsy. Archives of physical medicine and rehabilitation. Vol .91, pp. 1-8, 2010.

[10] D. L. Ines, G. Abdelkader. "Mixed reality serious games: The therapist perspective", Proceedings in IEEE 1st International Conference on Serious Games and Applications for Health (Dublin, Ireland), pp. 1-10, 2011 
[11] G. C. Burdea, A. Jain, B. Rabin, R. Pellosie, and M. Golomb, "Long-term hand telerehabilitation on the PlayStation 3: benefits and challenges". Conference proceedings: Annual International Conference of the IEEE Engineering in Medicine and Biology Society. IEEE Engineering in Medicine and Biology Society. Conference. (Bosto, USA), pp. 18351838, 2011.

[12] C. Franco, A. Fleury, P. Y. Gumery, B. Diot, J. Demongeot, N. Vuillerme. iBalance-ABF: a smartphone-based audio-biofeedback balance system, IEEE transactions on bio-medical engineering, vol. 60, pp. 211-215, 2013.

[13] I. C. Jeong, J. Finkelstein. Introducing a practical approach for non-invasive blood pressure monitoring during home-based telerehabilitation exercise program. IEEE Pointof-Care Healthcare Technologies, pp. 164-167, 2013.

[14] M. Piqueras, E. Marco, M. Coll, F. Escalada, A. Ballester, C. Cinca. Effectiveness of an interactive virtual telerehabilitation system in patients after total knee arthoplasty: a randomized controlled trial. Journal of Rehabilitation Medicine, vol. 45, pp. 392-396, 2013.

[15] C. Metcalf, R. Robinson, A. Malpass, T. Bogle, T. Dell, C. Harris, Markerless motion capture and measurement of hand kinematics: validation and application to home-based upper limb rehabilitation. IEEE Transactions on
Biomedical Engineering, vol. 60 (8), pp. 2184 -2192, 2013.

[16] S. M. Linder, A. B. Rosenfeldt, A. Reiss, S. Buchanan, K. Sahu, C. R. Bay, et al. The home stroke rehabilitation and monitoring system trial: a randomized controlled trial, International journal of stroke, vol. 8, pp. 46-53, 2013.

[17] D. O. Andrade, G. Fernandes, M. Junior, V. C. Roma, R. C. Joaquim, G.A.P. Caurin, Rehabilitation Robotics and Serious Games : An Initial Architecture for Simultaneous Players. Proceedings In Bioseñales y Biorobotics Conferencias (Rio de Janeiro, Brasil), pp. 1-6, 2013.

[18] G. Ligorio and A. M. Sabatini, "Extended Kalman filter-based methods for pose estimation using visual, inertial and magnetic sensors: comparative analysis and performance evaluation.," Sensors (Basel)., vol. 13 (2), pp. 1919-41, 2013.

[19] G. Roussel, L. Bourgois, M. Benjelloun, and G. Delmaire, "Estimation of a semi-physical GLBE model using dual EnKF learning algorithm coupled with a sensor network design strategy: Application to air field monitoring," Inf. Fusion, vol. 14(4), pp. 335-348, 2013.

[20] Zhang H, Dai G, Sun J, and Zhao Y. Unscented Kalman filter and its nonlinear application for tracking a moving target. Optik - International Journal for Light and Electron Optics, vol 124(20), pp. 4468-4471, 2013. 